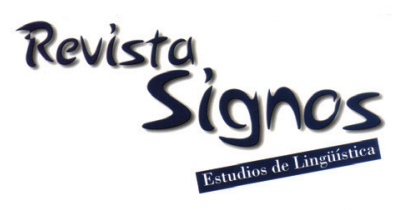

\title{
El lenguaje para enseñar y aprender las Ciencias Naturales: Un caso de oportunidades perdidas para la formación ciudadana
}

\author{
The language for teaching and learning Natural Science: \\ A case of missed opportunities for citizenship education
}

\section{Diana Chamorro}

Universidad del NorTe

Colombia

dchamorro@uninorte.du.co
Norma Barletta

Universidad del Norte

Colombia

nbarlett@uninorte.du.co

Jorge Mizuno

UNIVERSIDAd DEL NorTE

Colombia

jmizzuno@uninorte.du.co

Recibido: 1-XI-2011 / Aceptado: 9-VIII-2012

\section{Resumen}

Este artículo presenta un análisis de la interacción discursiva: maestro-texto escolaralumno en el desarrollo de los temas 'El agua' y 'El aire' en un curso de octavo grado. El objetivo es analizar en qué medida las características discursivas de un texto escolar de Ciencias Naturales, mediadas por el discurso del docente, facilitan la comprensión de los conceptos y contribuyen a la formación ciudadana. La metodología combina la etnografía y el análisis del discurso. El lenguaje del texto escolar se analiza desde categorías de la metafunción experiencial de la Lingüística Sistémico Funcional: metáfora gramatical, transitividad y ergatividad. En el análisis del discurso en el aula, se tuvieron en cuenta, a nivel de cláusula, las funciones del habla construidas en la metafunción interpersonal, y a nivel de segmentos discursivos, los patrones de interacción incluyendo la secuencia: Interrogación, Respuesta y Evaluación (IRE). Los resultados indican que el lenguaje del texto escolar se caracteriza por la presencia de procesos materiales no ergativos y el empleo frecuente de nominalizaciones. La 
maestra utiliza reiteradamente la secuencia IRE, caracterizada por preguntas por dato y órdenes. El lenguaje de los alumnos imita las vaguedades del discurso de la maestra y el texto, sin asomo de elaboración y criticidad. Estos hallazgos permiten concluir que algunos rasgos discursivos del texto y el lenguaje empleado por la maestra, dificultan la comprensión de los conceptos estudiados y no fomentan en los estudiantes competencias que les posibiliten una participación ciudadana informada y consciente de su rol en la sociedad.

Palabras Clave: Análisis del discurso, Lingüística Sistémico Funcional, texto escolar, formación ciudadana, discurso en el aula.

\begin{abstract}
This paper presents an analysis of the teacher-textbook- student interaction that takes place during the development of the topics 'Water' and 'Air' in eighth grade. The purpose is to analyze to what extent the discourse features of a Natural Science school textbook, mediated by the teacher's discourse, facilitate the students' understanding of natural events and contribute to the development of citizenship competences. The methodology of the study combined classroom ethnography and discourse analysis. The language of the textbook is analyzed from the perspective of the experiential metafunction within Functional Systemic Linguistics; namely, grammatical metaphor, transitivity and ergativity. At the clause level, classroom discourse was analyzed in terms of the speech functions that realize the interpersonal metafunction. At the level of discourse segments, patterns of interaction including Interrogation-ResponseFeedback (IRF) sequences were examined. Results suggest that the language of the textbook contains a large number of non-ergative material processes and a large number of nominalizations. The teacher repeatedly resorts to IRF sequences, in which she gives orders and asks for specific information. The language of the students tends to imitate many of the features of the language of the text and of the teacher, without evidence of elaboration and criticism. These findings suggest that some linguistic features of the text, as well as the language used by the teacher, do not (neither) facilitate the understanding of the concepts under study, nor do they (nor) foster competences among students that would enable them to exercise informed and conscious citizenship.
\end{abstract}

Key Words: Discourse analysis, Functional Systemic Linguistics, citizenship education, textbook, classroom discourse. 


\section{INTRODUCCIÓN}

En las instituciones educativas un objetivo fundamental debe orientarse a proveer el dominio de las herramientas semióticas (orales y escritas) que les permitan a los individuos tanto apropiarse del conocimiento y ponerlo en práctica como construirse a sí mismos y a una sociedad más justa y solidaria.

Ocuparse del ser social es básicamente preocuparse del lenguaje. En el proceso de adquisición de la lengua, un niño se incorpora a la subcultura a la que pertenece mediante su apropiación del lenguaje de dicha cultura. Parte de lo que debe hacer el niño en su desarrollo, es apropiarse del lenguaje escrito, ser capaz de comprender y producir textos, es decir, saber leer y escribir. Por tanto, los maestros han de orientar y enfatizar la lectura y escritura en cada una de las disciplinas ya sea como historiadores, científicos o matemáticos (Biancarosa \& Snow, 2004).

El aprendizaje de las ciencias implica entonces la apropiación y aplicación de los lenguajes propios de cada una de ellas. Estos lenguajes son diferentes del lenguaje de la cotidianidad de los estudiantes en los espacios del hogar, el barrio, los juegos. El discurso científico-académico mediante el cual se reconstruye la experiencia natural, física, social y biológica en la escuela, se caracteriza por un grado cada vez mayor de generalización y abstracción que requiere una intervención pedagógica consciente. Este proceso ontogenético tradicionalmente ha estado mediado por los discursos de los maestros y las maestras y el texto escolar.

De acuerdo con Halliday (2009), en la escuela hay una socialización que se caracteriza por normas diferentes de aquella del hogar. Por ejemplo, el conocimiento se organiza y se socializa con rituales propios de la institución, cadenas de intercambios con una estratificación marcada, control y evaluación de la actuación, lo cual determina o se vuelve el criterio para el éxito.

Por otro lado, la escuela debe formar individuos con los recursos semióticos y las estrategias necesarias para convertirse en ciudadanos capaces de continuar con su proceso de aprendizaje a lo largo de la vida, desarrollar su identidad, defender sus derechos, acceder y contribuir a los bienes y servicios de la comunidad, en últimas, participar activamente en la construcción de una sociedad justa y equitativa. Obviar esta tarea es crear espacios para la desigualdad en el desarrollo social y económico de las sociedades.

En un país como Colombia, envuelto en una lucha armada de varias décadas, una educación que permita a los jóvenes conocer y hacer uso de las prácticas democráticas, es una prioridad. De ahí que el Ministerio de Educación de Colombia (MEN) haya definido metas para implementar la educación ciudadana en las escuelas, así como unos estándares nacionales orientados a desarrollar la capacidad para realizar diversos procesos mentales fundamentales en el ejercicio ciudadano, entre los cuales se destacan 
las capacidades y habilidades esenciales para establecer un diálogo constructivo con las otras personas, y la capacidad para manejar conflictos pacífica y constructivamente (MEN, 2004).

Esto significa que en la formación en ciencias, en lenguaje y en ciudadanía deben estar imbricadas acciones pedagógicas que sistemáticamente lleven al desarrollo de las competencias que los jóvenes necesitan para su futuro y el de sus comunidades. Los maestros y maestras tienen a su cargo la función de mediar en este proceso y muchas veces lo hacen con la ayuda del texto escolar.

Los estudios que se han centrado en el libro de texto (Vallejos Llobet, 2004; Oteíza, 2006, 2009; Natale, 2009) han identificado una serie de rasgos discursivos que los caracterizan. Por ejemplo, las secuencias narrativas y descriptivas sin relaciones causales (Atienza, 2007); imágenes que refuerzan prejuicios, estereotipos y exclusiones de ciertos grupos (Ramírez, Gaspar, Figueredo \& Perales, 2005); tratamiento metafórico de la causalidad (García, 2004); la ausencia de explicitación de las operaciones discursivas, especialmente en los textos de matemáticas (Monti, 2004); la manipulación ideológica de la historia mediante las imágenes que son utilizadas para dar prominencia o silenciar los aspectos o eventos particulares según los intereses de los grupos más poderosos (Oteíza, 2006); la extensión de los textos, el vocabulario técnico y las referencias a fenómenos que suelen ser desconocidos (Natale, 2009). Con pocas excepciones (Colectivo Urdimbre, 2000; Barletta, 2002; Chamorro, Mizuno \& Moss, 2003; Mizuno \& Moss, 2006; Natale \& Stagnaro, 2008; Chamorro \& Barletta, 2009) estas características de los textos no se han estudiado de forma dinámica, es decir, en interacción con los alumnos y con la mediación de los docentes.

El estudio que se describe a continuación busca analizar en qué medida las características discursivas de las secciones 'El agua' y 'El aire' del texto escolar Inteligencia Científica 8 (Salamanca, 2003), mediadas por el discurso del docente, facilitan la comprensión de los conceptos y contribuyen a la formación ciudadana de estudiantes de octavo grado. Para alcanzar nuestro objetivo, combinamos la etnografía en el aula y el análisis del discurso desde la perspectiva de la Lingüística Sistémico Funcional.

Las técnicas de la etnografía nos permiten registrar la interacción discursiva en el aula, es decir, la forma cómo la maestra organiza la clase, qué es lo que realmente busca que los estudiantes aprendan a partir de la información consignada en el texto y cuál es su intención formativa. Igualmente, permiten reconstruir la interacción discursiva entre los estudiantes, de estos con la profesora y con el texto escolar, de manera que, a partir del análisis del discurso, podamos describir cómo co-construyen o recrean los conceptos estudiados y qué comprenden de ellos.

El análisis del discurso desde la perspectiva de la Lingüística Sistémico Funcional resulta muy útil en contextos educativos gracias a que comprende el aprendizaje como un proceso esencialmente lingüístico. Así, esta perspectiva nos da las herramientas 
que nos permiten identificar y explicar qué elementos del lenguaje pueden tener una incidencia en el aprendizaje de los estudiantes en términos de éxito o fracaso (Halliday \& Hasan, 1991).

\section{Marco teórico}

El análisis que se propone se enmarca en la perspectiva sistémico-funcional del lenguaje, según la cual este es un recurso semiótico para significar o un potencial de significados (Halliday, 2003). Esta perspectiva analiza la forma cómo el lenguaje es utilizado para lograr propósitos en el ámbito social, empleando formas sistemáticas de conectar el contexto con la escogencia de formas lingüísticas particulares. El enfoque sistémico permite comprender cómo las características de un texto contribuyen a sus significados y a la producción de ciertos efectos. Los significados de que se ocupa esta perspectiva son de tres tipos: los experienciales, que son aquellos que construyen la representación del mundo real o imaginario; los interpersonales, relacionados con el tipo de transacción o interacción que se construye en un texto, así como las actitudes, juicios, posiciones y voces que se vislumbran a partir de el; y, los significados textuales, o la forma cómo está organizado el texto como un mensaje coherente. Es así como Halliday (2004) propone tres funciones intrínsecas del lenguaje, o metafunciones como prefiere llamarlas, que corresponden a cada uno de los tres tipos de significado arriba descritos. Estas metafunciones, la experiencial, la interpersonal y la textual, se realizan simultáneamente tanto a nivel de texto como a nivel de la configuración gramatical de la cláusula. Desde esta perspectiva, leer, escuchar o comprender un texto de manera eficaz es ser capaz de: comprender los procesos a los que se hace referencia, el rol de los participantes en ellos y las circunstancias (tiempo, causa) en las que se desarrollan los procesos; comprender la relación entre los procesos o entre los participantes; reconocer la función del habla, los tipos de promesas, ofrecimientos, demandas, preguntas, actitudes y juicios involucrados y las características retóricas que lo constituyen como un acto simbólico; comprender el valor y centralidad del mensaje, y la coherencia entre cada una de las partes del texto (Halliday \& Hasan, 1991). En este artículo presentaremos resultados solamente con respecto a las dos primeras metafunciones.

Conceptos fundamentales en la Lingüística Sistémico Funcional son las nociones de campo, tenor y modo para describir la variación del contexto de situación (Halliday $\&$ Hasan, 1991). Campo se refiere a la actividad social que se está realizando mediante el lenguaje, para el caso de este artículo, el aula; tenor, cubre la relación entre los participantes y su estatus en la interacción, es decir, la interacción pedagógica en el aula; y modo, implica el papel o función del lenguaje en la situación. El campo, el tenor y el modo se realizan lingüísticamente mediante las tres metafunciones antes descritas. Nuestro análisis de algunos aspectos de las funciones experiencial e interpersonal nos permiten describir el registro del texto escolar y de la interacción en el aula. 


\subsection{Metafunción experiencial}

La metafunción del lenguaje que construye la experiencia, es decir, la transforma en significados, es la metafunción experiencial. Esta función se cumple en parte mediante el sistema de la transitividad, que se puede definir como los recursos gramaticales que "reflejan e imponen orden a la variación y flujo interminable de eventos" (Halliday, 2004: 170, traducción nuestra). Este sistema construye la experiencia mediante seis tipos de procesos, que determinan el tipo de cláusula. En de la Lingüística Sistémico Funcional, Halliday utiliza la cláusula como unidad básica de análisis, la cual tiene como núcleo un proceso. Según el tipo de proceso, las cláusulas se clasifican en seis tipos: cláusulas materiales, relacionales, mentales, existenciales, verbales y conductuales. Cada tipo de cláusula configura tipos particulares de participantes (ver Tabla 1).

Tabla 1. Tipos de cláusula según el proceso.

\begin{tabular}{|l|l|l|}
\hline Cláusulas & Significado & Participantes \\
\hline Material & $\begin{array}{l}\text { Hacer y ocurrir } \\
\text { Crear y transformar }\end{array}$ & Actor, meta, beneficiario, rango \\
\hline Relacional & $\begin{array}{l}\text { Relación entre dos entidades con un vínculo } \\
\text { entre ellas }\end{array}$ & $\begin{array}{l}\text { Portador y atributo } \\
\text { Identificado e identificador }\end{array}$ \\
\hline Mental & Sentir, pensar y percibir & Sensor y fenómeno \\
\hline Verbal & $\begin{array}{l}\text { Intercambio de significados simbólico: decir y } \\
\text { simbolizar }\end{array}$ & $\begin{array}{l}\text { Hablante, receptor, objetivo, } \\
\text { verbalización }\end{array}$ \\
\hline Existencial & Existencia de un fenómeno & Existente \\
\hline Conductual & Conductas psicológicas y fisiológicas & Ser consciente \\
\hline
\end{tabular}

La escogencia de un determinado tipo de proceso en una cláusula así como de sus correspondientes participantes, implica una forma particular de interpretar y re-construir la realidad. No es lo mismo reconstruir la realidad en términos de 'manifestantes resultaron heridos el sábado', que 'policía hirió a dos manifestantes el sábado'. En el primer ejemplo, la cláusula establece una relación entre un portador (manifestantes) y un atributo (heridos). En el segundo, un actor concreto (policía), mediante un proceso material, introduce una transformación en un participante concreto (manifestantes).

La transitividad construye la experiencia a partir de los diferentes tipos de proceso relacionados en la Tabla 1, interpretados desde dos modelos: el transitivo que interpreta el evento en términos de transmisión, y el ergativo que lo interpreta en términos de causación. Por ejemplo, la cláusula 'el ambiente se contaminó' sugiere que el ambiente realiza las acciones que provocan su contaminación. Es de notar que el proceso contaminar implica una transformación, la cual se extiende al ambiente; sin embargo, la cláusula no explicita el agente externo que causa la contaminación. Esta, por lo tanto, es una cláusula no-ergativa. En contraste, la cláusula 'la fábrica contamina el ambiente' explicita el actor del proceso material 'contaminar' (la fábrica) 
y es claramente el agente externo causante de la contaminación. Por tanto, es una cláusula ergativa.

\subsection{Metafunción interpersonal y patrones de interacción}

Simultáneamente con las otras metafunciones, el lenguaje construye una relación entre el hablante o escritor y el interlocutor o lector. La metafunción interpersonal es aquella mediante la cual el lenguaje construye el discurso como un evento interactivo, asignando un rol para el hablante o escritor, y uno para la audiencia o lector (Halliday, 2004). En dicho proceso se pueden intercambiar bienes o servicios, o información; tanto los primeros como lo segundo se pueden o bien dar o bien recibir. La combinación de estas variables del intercambio produce cuatro tipos posibles de funciones: se puede dar servicios o bienes en forma de Ofrecimientos; se puede dar información mediante Afirmaciones; igualmente, se pueden solicitar bienes o servicios en forma de Órdenes; y se puede solicitar información mediante Preguntas. Cada uno de estos actos puede realizarse mediante diversos tipos de escogencias lingüísticas. Por ejemplo, un Ofrecimiento de un bien se puede representar mediante la escogencia de una forma interrogativa (por ejemplo, ¿les puedo ayudar?). Igualmente, es posible dar una Orden mediante una forma interrogativa (por ejemplo: ¿podrían responder estas preguntas rápidamente?).

Una función realizada por el hablante constituye un rol particular, y a su vez, constituye al oyente con quien se interactúa. Así, una Orden espera una respuesta en términos de un ejecutor de un comando. Un Ofrecimiento implica un interlocutor que acepte dicha oferta y responda ya sea verbal o no verbalmente de forma correspondiente. La combinación de estos roles en una secuencia de intercambio de forma repetitiva constituye patrones de interacción que caracterizan la relación entre los participantes.

\subsection{Lenguaje de la ciencia}

Cuando hablamos del discurso de las ciencias, la mayoría de los docentes pensamos en el vocabulario. En realidad, el vocabulario no es la dificultad, más bien esta subyace en la gramática, la cual junto con el vocabulario técnico, logran un efecto global en la complejidad de los textos de ciencias. Halliday (1993) sugiere siete características de los textos de ciencias, que contribuyen a la dificultad de estos: definiciones entrelazadas, taxonomías técnicas, expresiones especiales, densidad léxica, ambigüedad sintáctica, discontinuidad semántica y metáfora gramatical. Por definiciones entrelazadas entiende las definiciones que utilizan conceptos definidos hace un instante, para entender un nuevo concepto. Normalmente en una definición de ciencias, podemos encontrar hasta cuatro conceptos entrelazados en una misma definición, lo cual produce una carga cognitiva bastante grande al estudiante. Las taxonomías técnicas se refieren a la característica de las ciencias de organizar los conceptos en categorías, que no son simplemente grupos de términos relacionados sino construcciones de alto nivel en las que cada término tiene un valor funcional. 
En su evolución, las ciencias han desarrollado formas especiales de expresar los conocimientos, es decir, van construyendo una gramática propia en la que juegan un papel importante la densidad léxica, la ambigüedad sintáctica y la metáfora gramatical. La primera se refiere a la densidad de información en cualquier pasaje de un texto según la forma en que los ítems léxicos (palabras que portan contenido/ significado) se han incluido en la estructura gramatical. La relación de medición se establece entre el número de ítems léxicos por cláusula. La ambigüedad sintáctica se relaciona con la utilización de expresiones que resultan ambiguas, como por ejemplo, en la oración 'el cáncer del pulmón está claramente asociado con el fumar', en donde 'está claramente asociado' puede interpretarse como la causa o el efecto de fumar. Tanto la ambigüedad como la densidad léxica son productos de la utilización de la metáfora gramatical, aspecto del que nos ocuparemos en la siguiente sección. Por último, Halliday referencia la discontinuidad semántica que ocurre cuando el autor realiza saltos semánticos, asumiendo que el lector puede seguirlos, sin problema, y llegar a una conclusión. Los textos así construidos se presentan como inconexos o aislados, el lector debe establecer las conexiones eliminadas o dadas por conocidas, lo cual no siempre es el caso de los estudiantes.

\subsection{Metáfora gramatical}

En el lenguaje científico es muy común recurrir a abstracciones, generalizaciones y metáforas gramaticales para referirse a fenómenos sociales y naturales. La metáfora gramatical consiste en "la substitución de una clase gramatical, o una estructura gramatical por otra" (Halliday, 1989: 26, traducción nuestra). La nominalización, como metáfora gramatical, alude a procesos y propiedades en forma de sustantivos en vez de verbos y adjetivos. Mediante ella "se mantiene inmóvil la realidad para permitir la observación y experimentación” (Halliday \& Martin, 1993: 15, traducción nuestra). Los procesos y las propiedades se objetivizan y se presenta un mundo en el que los objetos predominan y los procesos sirven simplemente para definir y clasificar. Un proceso o evento objetivizado se presenta como un hecho acabado, incambiable, que no puede ser cuestionado ni refutado sino que debe ser aceptado por el lector como la realidad (Chamorro et al., 2003). Este uso es una característica del lenguaje de la ciencia, ya que permite estructuras más compactas y eliminar información que se supone ya es conocida por un experto en el área del saber.

En la cláusula 'La actividad industrial genera contaminación en el ambiente', se ha inmovilizado una realidad compleja que hace alusión a unas personas, instrumentos y procesos que tienen lugar en una determinada industria, todo lo cual se ha compactado en la nominalización 'actividad'. Esto exige la reconstrucción del agente que realiza los procesos, el tiempo en que se llevan a cabo y el aspecto. Cuando se utiliza esta forma como punto de partida de la cláusula, se realizan afirmaciones sobre la realidad empacada en la nominalización, sin necesidad de señalar agentes humanos responsables. En el discurso científico y académico la nominalización permite avanzar 
la argumentación o explicación puesto que normalmente la información compactada ya es conocida de manera suficiente por los participantes en la comunicación. Sin embargo, para un lector inexperto (el caso de los estudiantes), la metáfora gramatical se ha detectado como un problema para la comprensión de lectura (Moss, Mizuno, Ávila, Barletta, Carreño, Chamorro \& Tapia, 2003).

\subsection{Formación ciudadana}

La formación ciudadana debe ser una de las principales preocupaciones de la escuela. En este contexto:

"la formación debería estar orientada a ayudar a los estudiantes a adquirir el conocimiento, habilidades y valores necesarios para funcionar de manera eficaz en la cultura local, regional, nacional y la cultura de la comunidad global" (Banks, 2008: 129, traducción nuestra).

Es decir, dotar a los estudiantes del conocimiento y la capacidad para identificar los problemas y tomar decisiones que les permitan realizar acciones reflexivas, individuales o colectivas, fundamentadas en valores, de manera que los estudiantes puedan construir un proyecto ético y de participación cuyo objetivo es hacer posibles para todos, los derechos humanos (Toro, 2009). Entender, además, que el orden social no es natural, sino una creación de los seres humanos, y, por lo tanto, susceptible de ser transformado. Es precisamente esta capacidad de poder participar en la creación, sostenimiento o modificación de los órdenes de la sociedad lo que nos hace ciudadanos. Nuestra actuación política debe desembocar en el fortalecimiento de los bienes públicos esenciales, para lo cual se necesitan competencias de debate que gestionen la convergencia y co-construcción de agendas colectivas para lograr cambios que favorezcan a todos.

El papel del lenguaje y de las competencias argumentativas y propositivas es fundamental para ejercer y reclamar los derechos, así como también para el desarrollo de la solidaridad, el respeto, la tolerancia y, en especial, el cuidado de los otros y del planeta. Estas competencias deben desarrollarse en la escuela de forma transversal en las actuaciones e intercambios diarios de los educandos de manera que mediante la reflexión y la discusión conjunta puedan establecer las implicaciones de sus acciones (individuales y colectivas) en la sociedad.

\section{Metodología}

Para alcanzar nuestro objetivo orientado a analizar en qué medida las características discursivas de un texto escolar de Ciencias Naturales, mediadas por el discurso del docente, facilitan la comprensión de los conceptos propios de las Ciencias Naturales y contribuyen a la formación ciudadana de estudiantes de octavo grado, combinamos etnografía (Rockwell, 1985; Martínez, 1991; Goetz \& Lecompte, 1998) con análisis del discurso desde la perspectiva de la Lingüística Sistémico Funcional (Halliday, 1993). 
El estudio etnográfico nos permitió registrar en audio y en diarios de campo la interacción discursiva en el aula entre una maestra de Ciencias Naturales, el lenguaje con el que se desarrollaron los temas ' $\mathrm{El}$ agua' y ' $\mathrm{El}$ aire' en el texto escolar Inteligencia Científica 8 (Salamanca, 2003) y 32 estudiantes (18 niñas y 14 niños) de octavo grado en una institución educativa pública de un municipio del Caribe colombiano. Estos estudiantes se caracterizan por pertenecer a un estrato socioeconómico bajo y por proceder de hogares cuyos padres tienen pocos años de escolaridad.

Para la recolección de la información relacionada con la interacción en el aula, utilizamos técnicas típicas de la etnografía como la observación no participante, el diario de campo y las entrevistas en profundidad. Observamos 8 horas de clase consecutivas, tiempo en el que se desarrollaron ambos temas. Cada observación fue llevada a cabo por dos profesores investigadores quienes las grabaron, tomaron notas y las transcribieron de manera que pudiéramos tener un registro sistemático de lo que acontecía y realizar, posteriormente, los análisis. Al final de las ocho observaciones, recogimos los exámenes aplicados por la docente a los estudiantes para tener evidencias del tipo de discurso que manejaban los estudiantes al final del desarrollo del tema.

Cada observación se transcribió en un formato de 4 columnas en el que identificamos: Turno de habla, Sujeto (Profesor o Alumno), Interacción en el aula y una última columna denominada Análisis. Así, teníamos la reproducción de la interacción en el aula en 'segmentos discursivos' que podíamos categorizar.

Para el análisis de las observaciones, nos fundamentamos en la metafunción interpersonal que nos permitiría caracterizar los roles en el intercambio de información en el aula entre maestra y alumnos, para lo cual nos centramos en la identificación de las funciones de habla utilizadas tanto por la maestra como por los estudiantes. Asimismo, nos apoyamos en el trabajo adelantado por Sinclair y Coulthard (1975) y Cazden (2001) para la identificación y análisis de las secuencias y el tipo de relación que se establece en la interacción. En el proceso da categorización del discurso de la maestra y los alumnos, se utilizaron categorías identificadas por otros autores, como es el caso de Andamiaje, pero también emergieron otras nuevas. Para asegurar la validez de este proceso recurrimos a la triangulación de los análisis (Cohen \& Manion, 1994).

En cuanto al análisis del lenguaje del texto escolar, lo realizamos empleando las categorías utilizadas en la perspectiva de la Lingüística Sistémico Funcional y que aluden a la metafunción experiencial: transitividad, ergatividad y metáfora gramatical. El análisis de cada uno de estos aspectos lo realizamos cláusula a cláusula, es decir, se analizaron cada uno de los segmentos discursivos del texto para identificar los rasgos discursivos mencionados. Los análisis se realizaron por parejas de investigadores (3 parejas) y luego eran discutidos en la mesa de trabajo (6 investigadores) con el fin de contrastarlos y garantizar así su confiabilidad. Como paso final, se realizó una contrastación entre los datos provenientes del análisis del texto escolar, de la maestra y de los alumnos. 


\section{Resultados}

\subsection{Metafunción experiencial: Transitividad y ergatividad en el texto}

El análisis de transitividad realizado a las secciones 'El agua’ y 'El aire’ nos permitió identificar 114 cláusulas distribuidas así: 55 cláusulas materiales, 36 relacionales, 7 conductuales, 7 mentales, 7 existenciales y 2 verbales. Entre los Actores de los procesos materiales (Halliday, 1993; Moss et al., 2003) solo tres son personas, dos de ellos en instrucciones dirigidas a los lectores; es decir, en la información acerca del agua y el aire, solo hay un Actor humano; de esta manera, la responsabilidad humana por el cuidado del ambiente se ve diluida.

Por otra parte, el análisis ergativo (Halliday, 1993; Moss et al., 2003) muestra que de 55 procesos materiales identificados, 16 son no-ergativos, es decir, son procesos que se presentan sin mención de agente externo, como si fuesen auto-engendrados, por ejemplo, 'el agua escasea' (130.21); y 17 cuasi-ergativos, que sugieren por su forma un agente externo pero no lo explicitan, por ejemplo: 'Emplear automóviles menos contaminantes' (138.2). De esta manera, los procesos de contaminación del agua y del aire son presentados sin asignación de responsabilidad. Veamos cómo se distribuyen los procesos en algunos fragmentos (Tablas 2 y 3 ).

Tabla 2. Análisis de transitividad y ergatividad en un fragmento de 'El agua'.

\begin{tabular}{|l|l|}
\hline Texto: Inteligencia Científica, página $\mathbf{1 3 1}$ párrafo 4 & Análisis \\
\hline Contaminación del agua potable & P. Relacional \\
En algunas partes del mundo el agua no solo está escaseando, sino que su calidad tam- & P. Material \\
bién se está degradando. Los ríos de Polonia, Asia y América Latina están muy contami- & no ergativo \\
nados & P. Relacional \\
\hline
\end{tabular}


Tabla 3. Análisis de transitividad en un fragmento de 'El aire'.

\begin{tabular}{|c|c|c|}
\hline \multicolumn{2}{|c|}{ Texto Inteligencia Científica, página 136 Párrafo 4} & Análisis \\
\hline \multicolumn{2}{|c|}{$\begin{array}{l}\text { Contaminantes del aire } \\
\text { Los contaminantes más comunes en el aire son: }\end{array}$} & P. Relacional \\
\hline Contaminante & Ejemplos & \\
\hline Óxidos de carbono & $\begin{array}{l}\text { Monóxido de carbono }\left(\mathrm{CO}_{2}\right) \\
\text { Dióxido de carbono }\left(\mathrm{CO}_{2}\right)\end{array}$ & \\
\hline Óxidos de azufre & $\begin{array}{l}\text { Dióxido de azufre }\left(\mathrm{SO}_{2}\right) \\
\text { Trióxido de azufre }\left(\mathrm{SO}_{3}\right)\end{array}$ & \\
\hline Óxidos de nitrógeno & $\begin{array}{l}\text { Óxido nítrico }(\mathrm{NO}) \\
\text { Dióxido de nitrógeno }\left(\mathrm{NO}_{2}\right) \\
\text { Óxido nitroso }\left(\mathrm{N}_{2} \mathrm{O}\right)\end{array}$ & \\
\hline Compuestos orgánicos volátiles & $\begin{array}{l}\text { Metano }\left(\mathrm{CH}_{4}\right) \\
\text { Benceno }\left(\mathrm{CH}_{4}\right) \\
\text { Clorofluorocarburos }(\mathrm{CFC}) \\
\text { Halones (Contienen bromo) }\end{array}$ & \\
\hline Materia particulada suspendida & $\begin{array}{l}\text { Polvo, hollín (carbón), polen } \\
\text { asbesto, plomo, arsénico, } \\
\text { cadmio y sales de nitrato } \\
\left(\mathrm{NO}_{3}\right) \text {, gotitas de patículas } \\
\text { líquidas como el ácido sulfúrico } \\
\left(\mathrm{H}_{2} \mathrm{SO}_{4}\right) \text {, petróleo, plaguicidas }\end{array}$ & \\
\hline \multicolumn{2}{|c|}{ Los contaminantes del aire pueden clasificarse como } & P. Relacional \\
\hline \multicolumn{2}{|c|}{$\begin{array}{l}\text { Contaminantes primarios: aquellos que entran directamente al aire } \\
\text { como resultado de eventos naturales o actividades humanas. Ejemplo: el } \\
\text { dióxido de azufre expulsado en las actividades humanas }\end{array}$} & P. Material no ergativo \\
\hline \multicolumn{2}{|c|}{$\begin{array}{l}\text { Contaminantes secundarios: Aquellos que se forman en la atmósfera } \\
\text { como resultado de reacciones químicas entre un componente primario } \\
\text { con los componentes del aire. Ejemplo: el ácido sulfúrico }\end{array}$} & P. Material no ergativo \\
\hline \multicolumn{2}{|c|}{ El esmog fotoquímico: un gran contaminante del aire } & \\
\hline \multicolumn{2}{|c|}{$\begin{array}{l}\text { El esmog fotoquímico se forma al mezclar docenas de contaminantes primarios } \\
\text { y secundarios bajo la influencia de la luz solar. En teoría casi todas las } \\
\text { ciudades modernas presentan smog fotoquímico. Sin embargo } \\
\text { es más común que } \\
\text { se presente en aquellas en las que haya climas soleados, secos, con canti- } \\
\text { dades numerosas de vehículos. Ciudades con problemas graves de esmog } \\
\text { fotoquímico son los Ángeles, Denver, Sidney, México y Salt Lake City }\end{array}$} & $\begin{array}{l}\text { P. Material no ergativo } \\
\text { P. Material cuasiergativo } \\
\text { P. Relacional } \\
\text { P. Material no ergativo } \\
\text { P. Relacional }\end{array}$ \\
\hline
\end{tabular}

En ambos fragmentos prevalecen los procesos relacionales y los materiales ya sea no ergativos (se forma, se presente) o cuasiergativos (al mezclar docenas de contaminantes). Asimismo, se identifican y se categorizan los contaminantes. Esto corresponde a una de las funciones típicas de los libros de ciencias naturales, que consiste en presentar taxonomías, aunque muchas veces, como es el caso del ejemplo, 
no se explicita el criterio de la clasificación de los fenómenos. Los contaminantes del aire 'entran' y se 'forman'. El agua 'escasea' y su calidad 'se degrada'. La escogencia de proceso relacional representa el fenómeno de escasez y degradación como un estado al que se llega por sí mismo o, en términos de (Halliday, 2004: 211) "se desarrolla de forma inerte, sin inyección de energía". Las actividades humanas son representadas como circunstancia, pero no como agencia: el dióxido de azufre expulsado en las actividades humanas. Es una representación en la que los fenómenos se representan como autoengendrados o sin agencia externa identificable. Se expresa en dónde (en las actividades) pero no se explicita quién expulsa al dióxido de azufre.

\subsection{Metafunción experiencial: Lenguaje metafórico en el texto}

En el texto es común el empleo de metáfora gramatical en la forma de nominalización (171 en 114 cláusulas). La nominalización hace desaparecer a los actores responsables de los procesos y, además, elimina la información con respecto a tiempo y aspecto (acabado vs. inacabado). Por su parte, el uso de Actores inanimados (procesos nominalizados u objetos) le confiere vida propia a tales Actores. En el fragmento que presentamos a continuación, hemos subrayado las expresiones metafóricas donde la nominalización es el núcleo del grupo nominal y la mayoría de las veces se constituyen en nominalizaciones complejas, es decir, grupos nominales en los cuales hay dos o más nominalizaciones, o una nominalización modificada por tres o más ítems léxicos.

Tabla 4. Análisis de metáfora gramatical: Nominalizaciones.

\begin{tabular}{|l|l|}
\hline $\begin{array}{l}\text { Texto Inteligencia Científica, página 131, } \\
\text { párrafo 4 }\end{array}$ & Análisis \\
\hline Algunas causas de contaminación hídrica son: & \\
\hline $\begin{array}{l}\text { Vertimiento de residuos de fertilizantes y } \\
\text { plaguicidas usados en actividades agrícolas }\end{array}$ & $\begin{array}{l}\text { "Vertimiento" omite la expresión del agente que } \\
\text { realiza la acción de verter } \\
\text { "Actividades agrícolas" compacta actividades } \\
\text { como sembrar, recolectar, regar, abonar, arar }\end{array}$ \\
\hline $\begin{array}{l}\text { Vertimiento de sedimentos procedentes de la } \\
\text { erosión natural del suelo }\end{array}$ & $\begin{array}{l}\text { No se indica quién vierte, qué erosiona ni por } \\
\text { qué }\end{array}$ \\
\hline $\begin{array}{l}\text { Vertimiento de residuos de la actividad silvícola, } \\
\text { minera y de construcción }\end{array}$ & $\begin{array}{l}\text { No se indica quién vierte residuos, quién se } \\
\text { dedica a explotar los bosques, quién construye o } \\
\text { qué construye }\end{array}$ \\
\hline $\begin{array}{l}\text { Vertimiento de desechos orgánicos: heces } \\
\text { animales y humanas }\end{array}$ & $\begin{array}{l}\text { No se explicita quién vierte estos productos de } \\
\text { los animales y los humanos }\end{array}$ \\
\hline$\underline{\text { Vertimiento de residuos procedentes de la }}$ & $\begin{array}{l}\text { No se indica quien vierte todos estos productos, } \\
\text { ni en qué consisten las actividades industriales, de } \\
\text { qué tipo son ni quién las realiza }\end{array}$ \\
\hline
\end{tabular}

El uso sistemático de expresiones nominalizadas aunado a la presencia de procesos relacionales o materiales no ergativos (ver Tabla 3), hace más notable la tendencia a no dar representación a la injerencia de acciones humanas o eventos naturales que dieran cuenta de la degradación de la calidad del agua y su contaminación. 
En el siguiente pasaje (Tabla 5) se aprecia la interacción entre la transitividad, la ergatividad y la metáfora gramatical.

Tabla 5. Análisis de transitividad, ergatividad y metáfora.

\begin{tabular}{|l|l|}
\hline $\begin{array}{l}\text { Texto Inteligencia Científica 8, página 136, Párrafos } \\
\mathbf{1} \text { a } 3\end{array}$ & Análisis \\
\hline $\begin{array}{l}\text { El aire de nuestra atmósfera está compuesto principalmente } \\
\text { por nitrógeno y oxígeno gaseoso. También se encuentran } \\
\text { pequeñas cantidades de otros gases y partículas considera- } \\
\text { das contaminantes }\end{array}$ & P. Relacional \\
\hline $\begin{array}{l}\text { La mayoría de los contaminantes del aire provienen de los } \\
\text { automóviles, las plantas de energía, fábricas, cigarrillos y } \\
\text { otras fuentes relacionadas con las actividades humanas }\end{array}$ & $\begin{array}{l}\text { P. Relacional } \\
\text { La presencia y la agencialidad humana } \\
\text { se diluyen al expresarse como una } \\
\text { circunstancia y como un atributo de } \\
\text { "otras fuentes" }\end{array}$ \\
\hline $\begin{array}{l}\text { La exposición repetida a estos contaminantes de la atmós- } \\
\text { fera puede dañar el tejido pulmonar del ser humano, a las } \\
\text { plantas, los peces y otros animales, edificios, a los metales } \\
\text { y otros materiales }\end{array}$ & $\begin{array}{l}\text { P. Material } \\
\text { La nominalización "exposición" es- } \\
\text { conde la agencialidad del ser humano } \\
\text { como principal causante del daño al } \\
\text { tejido pulmonar y principal víctima del } \\
\text { mismo } \\
\text { El sistema para categorizar a los } \\
\text { afectados por la exposición a los con- } \\
\text { taminantes no es claro }\end{array}$ \\
\hline
\end{tabular}

\subsection{Metafunción interpersonal: Interacción en el aula}

A continuación nos ocupamos de analizar la interacción en el aula maestra-textoalumno para lo cual caracterizamos, en primera instancia, las maneras de hacer de la maestra en el aula; luego, presentamos el análisis de la interacción Maestro-TextoAlumno desde la perspectiva de la metafunción interpersonal; concluimos este apartado con el análisis de la interacción Alumno-Alumno.

La sucesión de clases observadas sobre los temas 'El agua' y 'El aire', así como el tema posterior (Los fluidos), permitieron establecer un patrón característico del desarrollo de las clases de Ciencias Naturales en el contexto de estudio. Al iniciar un tema la maestra construye lo que en términos de Martin (1993) sería un macrotema mediante el dictado de un grupo de preguntas que los estudiantes deben contestar. Estas preguntas son la columna espinal de las clases, pues alrededor de ellas se teje la interacción ya sea entre alumnos, o entre alumnos y maestra. La profesora no se construye como una 'dictadora de clases' en el sentido de que no presenta los temas o los explica en forma de monólogo. En su lugar, le concede al texto escolar un lugar preponderante como fuente del conocimiento para sus estudiantes, quienes deben interactuar directamente con el libro, comprenderlo y aprender de el, en lo que tal vez se reconoce un enfoque aparentemente constructivista del aprendizaje. 
En un primer momento, las preguntas se contestan por escrito al interior de los grupos y con base en la información del texto escolar. Durante este trabajo, la maestra da vueltas por el salón y se acerca esporádicamente a revisar el accionar de los grupos. Su labor consiste básicamente en escuchar la forma cómo han respondido las preguntas. Un segundo momento lo constituye la puesta en común en la que los alumnos leen las preguntas con las respectivas respuestas, y la maestra pide y/o suministra aclaraciones para toda la clase. Un tercer momento es la evaluación. En el caso particular de las clases observadas, los estudiantes debían contestar, por escrito y en parejas, un cuestionario dictado por la profesora.

Esta forma de organizar la clase nos lleva a describir dos tipos de interacción. Una entre la profesora y los alumnos, ya sea con los grupos pequeños o con la clase entera. La otra entre alumnos, ya sea al construir las respuestas al taller en la interacción con el libro, o durante la evaluación cuando debían recurrir a los conocimientos adquiridos.

\subsubsection{Interacción Maestra-Texto-Alumnos ${ }^{2}$}

En esta interacción se observa la prevalencia de las secuencias IRE (Sinclair \& Coulthard, 1975; Cazden, 2001), que, como afirma van Lier (1996), son características de las clases tradicionales. En ellas, la maestra preestablece la relación de intercambio de información mediante un listado de preguntas que entrega a los estudiantes; las preguntas tienen dos funciones: a) mediar la relación entre los estudiantes y el texto, b) regular la interacción de los estudiantes con la maestra, la cual está orientada a verificar que el estudiante reproduzca fielmente la información expresada en el texto. Así, la relación de intercambio se caracteriza por la solicitud de la maestra de una información que ya es conocida por ella. El estudiante cumple el segundo turno, por lo general intentando ajustarse a lo solicitado y esperado por la maestra, tratando de demostrar que halló la información y, finalmente, la maestra cierra la secuencia con una aprobación o desaprobación de lo dicho por el alumno. En términos de las cuatro funciones de habla que describe Halliday (ver 1.2.), la maestra solicita información en forma de Preguntas, y hace afirmaciones con respecto a la validez de las respuestas. Los interrogantes de la maestra, sin embargo, tienen una función de Orden puesto que la pregunta en una secuencia IRE es una señal para que el estudiante demuestre lo que sabe o lo que ha encontrado en el texto.

En el discurso de la maestra durante el desarrollo de los dos temas se identifica la siguiente tipología de preguntas según el tipo de información que solicitan: Dato (22), Aporte (19), Efecto (16), Causa (7), Definición (7), Aplicación (5), Evaluación (3), Conocimiento Previo (2), Justificación (1), Agente (1). 
Tabla 6. Tipo de preguntas formuladas por la maestra.

\begin{tabular}{|c|c|c|}
\hline Preguntas & \multicolumn{2}{|c|}{ Ejemplo } \\
\hline Dato & & $\begin{array}{l}\text { ¿Las plantas son seres vivos o seres inertes? } \\
\text { Seres vivos } \\
\text { Son seres vivos }\end{array}$ \\
\hline Solicita aportes & $\begin{array}{l}\text { I: } \\
\text { R: } \\
\text { E+ I: } \\
\text { R: } \\
\text { E: } \\
\text { R: } \\
\text { I: } \\
\text { R: }\end{array}$ & $\begin{array}{l}\text { A ver. Hable de la problemática del agua } \\
\text { Debido a los cambios climáticos que se dan en el planeta. } \\
\text { Debido a los cambios climáticos ¿Cuáles serían esas problemáticas? } \\
\text { Seño, escasez de agua } \\
\text { Escasez de agua } \\
\text { Demasiada agua, contaminación del agua potable } \\
\text { ¿Cómo podríamos decir algo de la escasez? A ver, de la escasez } \\
\text { Debido a los cambios climáticos en el planeta, existen momentos en } \\
\text { los que hasta una quinta parte del área total del planeta presenta sequía } \\
\text { severa }\end{array}$ \\
\hline Efecto & $\begin{array}{l}\text { I: } \\
\text { R: } \\
\text { R: } \\
\text { R: } \\
\text { R: } \\
\text { R: } \\
\text { E: }\end{array}$ & $\begin{array}{l}\text { ¿Cuáles serían los efectos de la contaminación del aire? } \\
\text { Bastante esmog } \\
\text { Daños a la salud humana } \\
\text { Daña los vegetales } \\
\text { Daña la vida acuática } \\
\text { Daña los materiales } \\
\text { O sea que daña todos los seres vivos }\end{array}$ \\
\hline Causa & $\begin{array}{l}\text { I: } \\
\text { R: } \\
\text { E+I: }\end{array}$ & $\begin{array}{l}\text { Cargadas de sangre ¿Por qué? } \\
\text { Mataderos } \\
\text { De los mataderos donde están lavando el ganado, corren las aguas sucias } \\
\text { de las mismas, eh, fábricas vierten todas esas aguas, esas mismas aguas } \\
\text { que van al río lo contaminan. ¿Puede el hombre evitar eso? }\end{array}$ \\
\hline Definición & $\begin{array}{l}\text { I: } \\
\text { R: } \\
\text { E: }\end{array}$ & $\begin{array}{l}\text { ¿Qué será erosión entonces? } \\
\text { Movimiento de los componentes del suelo } \\
\text { Movimiento de los componentes del suelo }\end{array}$ \\
\hline Aplicación & & $\begin{array}{l}\text { ¿Cómo evitaría usted la contaminación del aire? (Lee de la libreta) } \\
\text { Espérate, espérate, que esto viene de acá... el aire de nuestra atmósfera } \\
\text { está compuesto principalmente por nitrógeno y oxígeno. También se } \\
\text { encuentran pequeñas cantidades de otros gases y partículas considera- } \\
\text { das contaminantes. La mayoría de los contaminantes del aire provienen } \\
\text { de los automóviles, las plantas de energía, fábricas, cigarrillos y otras } \\
\text { fuentes relacionadas. La exposición repetida a estos contaminantes de la } \\
\text { atmósfera puede dañar el tejido pulmonar del ser humano, a las plantas, } \\
\text { los peces y otros animales, edificios, a los metales y otros materiales. La } \\
\text { evitaría no quemando basura, no fumando cigarrillo... }\end{array}$ \\
\hline
\end{tabular}

Las preguntas formuladas por la maestra no median la comprensión de la información presentada en el texto; se caracterizan por inducir a la reproducción textual de la información, especialmente un fragmento del fenómeno, como es el caso de las preguntas que solicitan un dato. Se podría pensar que una pregunta por Causa o por Efecto lleve al estudiante a realizar un proceso de análisis o de reflexión o evaluación, sin embargo, tales procesos cognitivos no se evidencian, ya que estas preguntas se limitan a reificar la centralidad del texto escolar en la clase, de tal forma que los estudiantes reproducen nominalizaciones, emplean un discurso cuasi ergativo y no ergativo, y afianzan un conocimiento cotidiano e ingenuo. Por ejemplo, en lo 
que se refiere a la pregunta de aplicación en la Tabla 6, los estudiantes la responden desde el contexto del texto, ya que la práctica en clase ha sido esa. De ahí que se destaca la reproducción casi literal, y la alusión a circunstancias que están fuera de su cotidianidad como son las fábricas y las plantas de energía. Solo en la última oración se evidencia, mediante el uso de la primera persona, algún indicio de posible compromiso ciudadano con el ambiente, en términos de 'la evitaría no quemando basura no fumando cigarrillo'.

En este intercambio de información, los estudiantes participan suministrando información, pero solo la requerida. Rara vez hacen preguntas o hacen ofrecimientos. Por lo general, una evaluación negativa lleva a una nueva secuencia, ya sea con el mismo alumno o con uno diferente. Hay que anotar que los alumnos cuando interactuaron con la maestra en pequeños grupos no parecían sentir temor de ser evaluados por ella, puesto que sus respuestas eran leídas de sus cuadernos, que a su vez eran copia casi textual del texto escolar.

Las secuencias completas de interacciones alrededor de cada pregunta comenzaban con la intervención de un alumno o alumna para proponer la pregunta que se intentaría contestar (ver ejemplo de la Tabla 7). Hemos denominado esta intervención Cuasiinicio puesto que, en realidad, corresponde al acuerdo implícito de seguir con el Macrotema impuesto por la profesora al principio de la clase en forma de cuestionario. Este Cuasiinicio, sin embargo, era autorizado muchas veces por la maestra, quien, mediante la repetición de la pregunta, daba una señal para que pudiera empezar a desarrollarse el asunto propuesto. La Evaluación positiva explícita de la secuencia IRE era suministrada por la maestra cuando los alumnos respondían en el nivel de exactitud o detalle que ella deseaba. Esta evaluación se marcaba básicamente mediante la repetición de la respuesta que la profesora consideraba apropiada.

Las interacciones con la profesora requieren un conocimiento meramente cotidiano, por ejemplo, los turnos 200, 204, 206, 207 son respuestas a preguntas que apuntan a describir los efectos de la contaminación, mas no los causantes, con lo cual la profesora se suscribe a la pauta del texto escolar (y la refuerza) que, como describimos arriba, sistemáticamente elimina agentes humanos responsables de fenómenos del mundo. 
Tabla 7. Interacción Maestra-Alumnos en el desarrollo completo de una pregunta.

\begin{tabular}{|l|l|l|l|}
\hline T & Interacción & S & Intervención \\
\hline 196 & C & A & Contaminación del agua potable \\
\hline 197 & I & P & A ver. ¿Qué pasa con la contaminación del agua? \\
\hline 198 & R & A & Este... No podríamos bebernos el agua \\
\hline 199 & I & P & ¿Las personas no más? \\
\hline 200 & R & A & Todas las personas y los animales \\
\hline 201 & I & P & ¿Y cómo se llama todo eso? \\
\hline 202 & R & A & Todos los seres vivos \\
\hline 203 & E + I & P & $\begin{array}{l}\text { Todos los seres vivos porque incluso si le echamos agua contaminada a } \\
\text { las plantas... ¿Las plantas son seres vivos o seres inertes? }\end{array}$ \\
\hline 204 & R & As & Seres vivos \\
\hline 205 & E+I & P & $\begin{array}{l}\text { Son seres vivos. Si usted le echa agua contaminada a las plantas, ¿qué les } \\
\text { pasa? }\end{array}$ \\
\hline 206 & R & As & Se muere \\
\hline 207 & R & A & Se le caen las hojas \\
\hline 208 & C & P & Entonces los seres vivos no podemos consumir el agua contaminada \\
\hline
\end{tabular}

Las preguntas en la interacción de la Tabla 7 apuntan a un nivel cognitivo muy básico, puesto que no hay preguntas de análisis, comparación, contrastación o evaluación. En términos vygotskianos este tipo de interacción no parece suceder dentro de una Zona de Desarrollo que pueda jalonar la formación de conceptos o de los procesos cognitivos. La interacción podría categorizarse como de Exhibición, tal vez por la presencia de los investigadores, pero no con relación a un conocimiento recién adquirido, sino como simulación de un diálogo pedagógico apacible, armonioso y sin sobresaltos, puesto que no hay desbalances, cuestionamientos, tiranía ni frustraciones. La secuencia, sin embargo, revela una preocupación por la taxonomía de lo seres y una relación causa-efecto simple y absolutista, así como unos roles predeterminados y estáticos en las relaciones entre los seres. Es la orquestación de una simulación de aprendizaje.

Igualmente, son notorios lo que hemos denominado andamiajes rastreros, y los descuidos conceptuales. El andamiaje rastrero es una estrategia de la maestra para obtener respuestas correctas de los estudiantes suministrándoles tanto apoyo que es imposible que los alumnos se equivoquen. En esta estrategia la maestra solo deja espacio para que los estudiantes digan una palabra que en ese punto es obvia. En los turnos 169 y 171 en la Tabla 8, la maestra prácticamente pone en labios de los estudiantes la palabra que quiere escuchar. Es dudoso que haya jalonamiento alguno o que realmente se produzca algún tipo de aprendizaje en este tipo de andamiaje. 
Tabla 8. Interacción Maestra-Alumnos: Andamiaje rastrero y descuido conceptual.

\begin{tabular}{|l|l|l|l|}
\hline T & Interacción & S & Intervención \\
\hline 161 & I & P & ¿Qué pasa con el ciclo del agua? A ver \\
\hline 162 & R & A & Es importante porque ayuda a mantener viva la tierra y... \\
\hline 163 & E- & P & Ś́, pero aquí cuando yo digo: explique el ciclo del agua \\
\hline 164 & R & A & Es cuando el agua se evapora, el viento la convierte en lluvia y nieve \\
\hline 165 & E + & P & $\begin{array}{l}\text { Sí. El agua evapora y sube, ¿verdad? Al subir el viento la lleva hacia la } \\
\text { atmósfera por las nubes. Ahí choca entre las gotas de ella y cae en forma } \\
\text { de precipitación o nieve y lluvia y nuevamente y llega y cae, ¿dónde? }\end{array}$ \\
\hline 166 & R & As & En los ríos, en los mares \\
\hline 167 & E+ & P & $\begin{array}{l}\text { En los ríos, en los mares y nuevamente empieza otro ciclo. Por eso es } \\
\text { que se llama... }\end{array}$ \\
\hline 168 & & P & Por eso es que en los libros aparece en círculo \\
\hline 169 & & P & Por eso es que se llama ¿qué? \\
\hline 170 & R & As & Ciclo \\
\hline 171 & & P & Porque no tiene principio ni... \\
\hline 172 & R & As & Fin. Final \\
\hline
\end{tabular}

El turno 165 contiene una imprecisión (descuido conceptual) con respecto al papel del viento en el ciclo del agua. No es sorprendente entonces que, a falta de otra información clara a la cual acudir, nueve de las 16 parejas de estudiantes que respondieron la evaluación escrita, hubieran reproducido en sus exámenes la inexactitud del discurso de la maestra como lo muestra el ejemplo (1):

(1)

P. Explique el ciclo del agua.

El ciclo del agua es:

- se evapora por los rayos del sol

- sube a las nubes por medio de la brisa

- cae en forma de lluvia o de nieve

- cayendo de nuevo a las fuentes de los ríos, (Esval. 3)

Otras tres evaluaciones reprodujeron, a su manera, la parte del texto que se refiere al ciclo del agua a pesar de que no responde a la pregunta: 'El agua dulce de la tierra se colecta, se purifica y distribuye de manera continua. El ciclo hidrológico: el agua dulce se distribuye de manera poco uniforme en el planeta' (Eval, 4). 'El ciclo del agua es dulce y se distribuye de manera poco uniforme en el planeta, la mayor parte es de agua salada (mares y océanos)' (Eval, 6). Estas respuestas sugieren la sumisión de los estudiantes al discurso del libro y al de la maestra, la falta de análisis y cuestionamiento, así como una interacción mecánica se limita a las superficialidades y construye conformismo. 


\subsubsection{Interacción Alumno-Alumno}

En estos intercambios los alumnos trabajan prácticamente de forma mecánica pero solidaria para encontrar las respuestas en el texto, ayudar a los compañeros a encontrar dónde está localizada la información, dictarse mutuamente lo que hay que copiar, incluyendo la puntuación, y terminar el taller propuesto por la maestra, ejemplos 2 y 3 :

(2)

T S Intervención

39 A3 Bueno, ahora sigo yo pues, eso cansa. De esmog fotoquímico son Los Ángeles, Denver

(3)

T S Intervención

46 A3 La quinta. Efectos de contaminación del aire. (...) de contaminantes... atmosféricos... pueden producir, pueden producir, dos

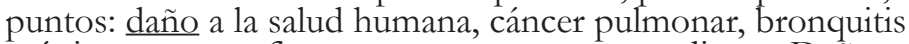
crónica, coma, enfisema, coma, trastornos cardiacos. Daño a los vegetales: daños directos a las hojas. Daños directos en las hojas. Punto seguido. Reducción en la ingestión de nutrientes. Punto aparte. Mayor susceptibilidad,

47 A2 ¿Qué?

48 A3 susceptibilidad

49 A2 ¿sus?

50 A3 con 'c', susceptibilidad para ser atacados por patógenos. Reducción en el rendimiento agrícola. Daño a la vida acuática.

51 A2 ¿Qué es eso?

52 A3 Daño a la vida acuática

53 A Nada más tiene que ser así

54 A3 Sofocamiento y muerte de los peces. Aparte. Disminución en la tasa de reproducción. Daño a los materiales. Daño a los materiales. La caída de hollín.

55 A2 Otra vez. La caída ¿de qué?

56 A3 Hollín. Hollín y suciedad en ropa y edificios requiere de una limpieza costosa. Punto aparte. Destrucción de la pintura exterior

Sobresale la buena disposición para trabajar y la forma como se organizan para realizar su tarea de forma operativa. Sin embargo, resalta también la falta de intercambio significativo con respecto a los contenidos, así como ausencia de construcción de sentido a partir de la información que están escribiendo.

En el trabajo en los grupos, la tarea básicamente consiste en transcribir en los cuadernos los apartes de texto que parecen contestar las preguntas de la maestra. Al hacerlo, los estudiantes conservan las formas discursivas no ergativas y metafóricas 
del texto. Cuando hay incomprensión no hay cuestionamiento sino sumisión, como cuando un alumno le dice a otro: 'nada más tiene que ser así', lo cual implica que no es necesario expandir la respuesta ni comprenderla. En el fragmento es evidente que, aunque no comprenden la palabra 'susceptibilidad', solo se detienen a aclarar la ortografía. Las respuestas en las evaluaciones a la pregunta sobre los efectos de la contaminación evidencian la forma algo primitiva y hasta errónea de cómo han comprendido, por ejemplo, los efectos de la contaminación que tan diligentemente copiaron en clase: 'pueden causar enfermedades en los pulmones' (Eval, 15); ‘daño a los materiales: Si no tenemos cuidado con ellos se dañan. Ejemplo: una ventana de hierro el aire contaminado la oxida' (Eval, 9); 'Bronquitis' (Eval, 7); 'el humo viene mediante los objetos q' se queman como por ejemplo: la basura, las llantas, el humo de los carros, el humo de los cigarrillos' (Eval, 2).

En la evaluación, varios alumnos retomaron las nominalizaciones 'daño’ y 'trastorno'. La nominalización ‘daño' fue la más utilizada (en cuatro de las dieciséis muestras) para describir los efectos de la contaminación. Sin embargo, las respuestas sugieren una limitación en la comprensión del proceso nominalizado. Por ejemplo, el enunciado 'Daño a los vegetales: causan daño directamente a las hojas porque pierden su color natural o naturalidad' (Esval, 14) muestra cómo los alumnos restringen el daño a un aspecto superficial. No fueron retomadas en las respuestas las nominalizaciones 'reducción' e 'ingestión' (reducción de la ingestión de nutrientes), 'susceptibilidad' (susceptibilidad de ser atacados por agentes patógenos), 'rendimiento' (reducción del rendimiento agrícola), 'disminución’ y 'reproducción' (disminución de la tasa de reproducción). La nominalización 'sofocamiento', fue utilizada incorrectamente en 'sofocamiento de estatuas y edificios' (Eval. 14). Este tratamiento superficial de un asunto tan vital para nuestra supervivencia en la tierra se evidencia también en la forma como los aprendices abordan preguntas que potencialmente podrían llevarlos a reflexionar más profundamente sobre su propia injerencia en los fenómenos:

(4):

T S Intervención

328 A ¿Cómo podemos proteger la capa de ozono?

329 A No contaminando

330 A Evitando la contaminación

El facilismo se expresa no solamente en la parquedad de las respuestas, sino también en el uso de la negación. Ella no aclara cuáles son las acciones que sí han de realizarse.

En resumen, no se evidencian avances en el uso del lenguaje de las ciencias, la exposición al lenguaje metafórico y encriptado del texto ha sido circulado en los grupos y en la clase, solo para ser consignado en las libretas y ser rechazado y reemplazado por el cotidiano al momento de dar cuenta de los conocimientos construidos. Esto 
no posibilita avances de tipo cognitivo y conceptual; los estudiantes no solo tienen que saber definir y clasificar el concepto de contaminación desde el punto de vista químico (tipos a partir de los contaminantes) sino saber especificar las cualidades esenciales y no esenciales para comprender dicha definición; establecer el rol que tiene el ser humano en las situaciones o eventos que posibilitan la contaminación; y establecer el papel actual y futuro que ellos desempeñarán en el entorno natural de su comunidad.

\section{CONCLUSIÓN}

El análisis realizado nos ha permitido establecer algunas características discursivas de las secciones 'El agua' y 'El aire' de un texto escolar de Ciencias Naturales, que aunadas al discurso del docente, dificultan la comprensión de los conceptos estudiados y no fomentan en los estudiantes unas competencias/habilidades que les posibiliten una participación ciudadana informada y consciente de su rol en su contexto social inmediato. El análisis del texto nos permitió establecer que:

- La mayoría de los Actores son objetos y nominalizaciones. Así, la responsabilidad humana por el cuidado del ambiente se ve diluida.

- El reiterado uso de la metáfora gramatical constituye una exigencia cognitiva alta para los estudiantes porque, para comprender el fenómeno a cabalidad, tienen que reconstruir el agente que realiza los procesos (de contaminación del agua y del aire), el tiempo en que se llevan a cabo y el aspecto verbal. Los estudiantes, que normalmente son lectores inexpertos y neófitos en los temas científicos que se desarrollan en la escuela, posiblemente tengan dificultades para recuperar la información faltante.

- Las actividades humanas son representadas como circunstancia, pero no como agencia. Los fenómenos como la contaminación y el vertimiento de desechos no se presentan como resultado de las acciones humanas; por tanto, se diluye la responsabilidad ciudadana y las posibilidades de acciones correctivas.

De acuerdo con el análisis de la interacción en el aula, la mediación de la maestra tiene como objetivo final identificar la información y transcribirla textualmente sin análisis, cuestionamientos o posibles implicaciones para la vida y el contexto de los estudiantes. Además, la forma como la maestra planteó la interacción texto-alumno niega a los estudiantes las posibilidades de elaborar una interpretación científica de los fenómenos y procesos involucrados en la contaminación del agua y del aire; tampoco les es posible construir un marco conceptual estructurado ni valorar en qué medida los seres humanos que hacen ciencia, los que generan e impulsan el desarrollo tecnológico y los usuarios de esos avances, son también responsables de la contaminación del entorno ambiental. 
En suma, el lenguaje del texto y la mediación adoptada por la maestra se constituyen en una instancia de oportunidades perdidas para que los estudiantes pudieran: tomar distancia de la explicación cotidiana de los eventos naturales y se acercaran a la explicación y comprensión científica de los mismos; aplicar e interpretar el concepto de contaminación en su contexto; identificar y analizar en su contexto las políticas ambientales para prevenir e intervenir en las acciones y situaciones de contaminación ambiental; identificar, discutir y plantear soluciones sobre los actores, acciones y procesos, situaciones que generan la contaminación del aire y el agua (mar) en su contexto; analizar críticamente los efectos de la contaminación del aire y el agua en la salud y en la economía de su población; e identificar y analizar su rol en su comunidad en relación con la problemática ambiental.

El estudio de las Ciencias Naturales en el contexto de la escuela no solo ha de fomentar la creatividad, el espíritu de indagación, sino que debe posibilitar la transición de la comprensión de los hechos cotidianos a otra más compleja, el conocimiento científico. Para que esta transición tenga lugar se hace necesario que el maestro conozca y haga conocer a los estudiantes el lenguaje propio de la disciplina y emplee estrategias que puedan llevar a una promoción de rol vinculante: análisis de casos, toma de decisiones con respecto al equilibrio del entorno natural. Así, la clase de Ciencias Naturales se constituye en el espacio para promover la reflexión crítica sobre los agentes, causas y condiciones que generan los problemas ambientales y analizar sus implicaciones sociales, culturales y económicas para la salud y las relaciones de los seres vivos, de manera que los estudiantes puedan no solo intervenir de manera informada en discusiones sobre temas científicos, sino también que puedan establecer la incidencia que tienen los conocimientos generados por la ciencia en la vida y en las relaciones de los seres humanos. 


\section{REFERENCIAS BIBLIOGRÁFICAS}

Atienza, E. (2007). Discurso e ideología en los libros de texto de ciencias sociales. Discurso y Sociedad, 1(4), 543-574.

Banks, J. A. (2008). Diversity, group identity, and citizenship education in a global age. Educational Researcher, 37(3), 129-139.

Barletta, N. (2002). El maestro, el texto y el alumno en una conversación para el aprendizaje. Zona Próxima, 3, 10-25.

Biancarosa, G. \& Snow, C. (2004). Reading next- A vision for action and research in middle and high school literacy: A report from Carnegie Corporation of New York. Washington, DC: Alliance for Excellent Education.

Cazden, C. (2001). Classroom discourse: The language of teaching and learning. Portsmouth, NH.: Heinemann.

Chamorro, D. \& Barletta, N. (2009). El lenguaje del texto escolar de ciencias naturales: Problemas para el aprendizaje. Bio-grafía: Escritos sobre Biología y su Enseñanza [en línea]. Disponible en: http://www.pedagogica.edu.co/revistas/ojs/index. php/bio-grafia/article/viewFile/156/126

Chamorro, D., Mizuno, J. \& Moss, G. (2003). Tergiversaciones y correspondencias: La metáfora y sus bemoles, Revista Latinoamericana del Discurso, 3, 29-47.

Cohen, L. \& Manion, L. (1994). Research methods in education. Londres: Routledge.

Colectivo Urdimbre (2000). Libros de texto y aprendizaje en la escuela. Sevilla: Diada Editores.

García, M. (2004). La construcción lingüística de la causalidad en el discursos científico. Ciencia de investigación y ciencia escolar. En P. Vallejos Llobet (Comp.), El discurso cientifico pedagógico: Aspectos de la textualización del "saber enseñado" (pp. 37-59). Bahía Blanca: Editorial de la Universidad Nacional del Sur.

Goetz, J. P. \& Lecompte, M. D. (1988). Etnografía y diseño cualitativo en la investigación. Madrid: Morata.

Halliday, M. A. K. (1989). Some grammatical problems in scientific English. Australian Review of Applied Linguistics. Supplement, 6, 13-37.

Halliday, M. A. K. (1993). Some grammatical problems in Scientific English. En M.A.K. Halliday \& J. R. Martin (Eds.) Writing science: Literacy and discursive power (pp. 69-85). Londres: The Falmer Press. 
Halliday, M. A. K. (2003). On language and linguistics. Londres: Continuum.

Halliday, M. A. K. (2004). An introduction to functional grammar. Londres: Edward.

Halliday, M. A. K. (2009). Language and education. Londres: Continuum.

Halliday, M. A. K. \& Hasan, R. (1991). Language, context and text: Aspects of language in a social semiotic perspective. Oxford: Oxford University Press.

Halliday, M. A. K. \& Martin, J. R. (1993). Writing science: Literacy and discursive power. Londres: The Falmer Press.

Martin, J. (1993). Technicality and abstraction: Language for the creation of specialized texts. En M. A. K. Halliday \& J. R. Martin (Eds.), Writing science: Literacy and discursive power (pp. 203-220). Londres: The Falmer Press.

Martínez, M. (1991). La investigación cualitativa etnográfica. Caracas: Texto.

Ministerio de Educación Nacional (2004). Estándares básicos de competencias ciudadanas. Formar para la ciudadania si es posible [en línea]. Disponible en: http://www. mineducacion.gov.co/1621/articles-116042_archivo_pdf4.pdf

Mizuno, J. \& Moss, G. (2006). La ideología en la interacción maestro-texto-estudiante en las clases de Ciencias Sociales y su repercusión en la educación ciudadana. Akademos, 8(2), 63-87.

Monti, C. (2004). La definición y la clasificación en el discurso pedagógico de la matemática: Dificultades y propuestas. En P. Vallejos Llobet (Comp.), El discurso cientifico pedagógico: Aspectos de la textualización del "saber enseñado" (pp. 77111). Bahía Blanca: Editorial de la Universidad Nacional del Sur.

Moss, G., Mizuno, J., Ávila, D., Barletta, N., Carreño, S., Chamorro, D. \& Tapia, C. (2003). Urdimbre del texto escolar: ¿Por qué resultan difíciles algunos textos? Barranquilla: Ediciones Uninorte.

Natale, L. (2009). Lo que los manuales escolares no dicen (y lo que los profesores debemos ayudar a comprender). Delta, 24, 645-656.

Natale, L. \& Stagnaro, D. (2008). Tengo una vaca lechera... La ganadería en los manuales escolares argentinos. Ponencia presentada en el Tercer Congreso Internacional Transformaciones Culturales, Universidad de Buenos Aires, Buenos Aires, Argentina.

Oteíza, T. (2006). El discurso pedagógico de la historia. Un análisis lingüistico sobre la construcción ideológica de la historia de Chile (1970-2001). Santiago, Chile: Frasis Editores. 
Oteíza, T. (2009). Solidaridad ideológica en el discurso de la historia: Tensión entre orientaciones monoglósicas y heteroglósicas. Revista Signos. Estudios de Lingüistica, 42(70), 219-244.

Ramírez, T., Gaspar, M., Figueredo, V. \& Perales, M. (2005). La cultura indígena en las ilustraciones de los textos escolares de las Ciencias Sociales de la segunda etapa de educación básica en Venezuela. Revista de Pedagogía, 26(75), 31-62.

Rockwell, E. (1985). Etnografía y teoría de la investigación educativa. México: Instituto Politécnico Nacional.

Salamanca, M. (2003). Inteligencia científica 8. Bogotá: Voluntad.

Sinclair, J. \& Coulthard, R. M. (1975). Towards an analysis of discourse: The English used by teachers and pupils. Oxford: Oxford University Press.

Toro, B. (2009). Participación y valores ciudadanos. Tesis para la formación política del ciudadano. En B. Toro \& A. Tallone (Coord.), Educación, valores y ciudadanía (pp. 23-28). Madrid: Organización de Estados Iberoamericanos para la Educación, la Ciencia y la Cultura (OEI), Fundación SM.

Vallejos Llobet, P. (2004) (Comp.). El discurso científico pedagógico: Aspectos de la textualización del "saber enseñado". Bahía Blanca: Editorial de la Universidad Nacional del Sur.

Van Lier, L. (1996). Interaction in the language curriculum: Awareness, autonomy and authenticity. Londres: Longman.

\section{NOTAS}

1 Las ejemplos tomados del texto analizado especifican el número de la página y el párrafo correspondiente, así: 130.2, significa página 130, párrafo 2 .

2 En esta sección empleamos las siguientes convenciones en los ejemplos: T: turno; S: sujetos; Inter: interacción; A: alumno; As: Alumnos; P: Maestra; I: Interrogación; R: respuesta; E: evaluación; E+: evaluación positiva; E-: evaluación negativa; C: cierre. 